\title{
A VIOLÊNCIA NO RIO DE JANEIRO: UM OLHAR SOBRE A POLÍTICA DE SEGURANÇA PÚBLICA EMPREGADA NO ESTADO
}

\author{
Antonio José Ferreira Gomes ${ }^{1}$
}

RESUMO: A violência no Rio de Janeiro é um fenômeno que vem crescendo de uma maneira significativa nas últimas décadas, tornando-se uma problemática que gera cada vez mais a necessidade de discussão no âmbito público, visto que causa uma preocupação expressiva em toda a população frente ao caos gerado pelo cenário de constantes guerrilhas. A partir daí, emerge uma preocupação em relação à necessidade de discussão das políticas públicas que atuam na contenção dos problemas gerados pela violência no Rio de Janeiro. A partir deste contexto, fazem-se necessárias reflexões sobre os pressupostos que norteiam a temática buscando a compreensão sobre como a violência neste cenário vem se construindo ao longo da história a partir das relações estabelecidas entre a população e o Estado bem como, a forma como as políticas públicas se interpõe nesta lógica construída ao longo do tempo. Então o objetivo principal do presente estudo é promover uma discussão sobre as políticas segurança pública empregadas no combate à violência no Rio de Janeiro. A metodologia utilizada é de perspectiva bibliográfica e abordagem qualitativa, com busca através de meio físico e digital nas bases de dados Scielo e Google Acadêmico. Em relação a segurança pública pode ser observada uma inversão de valores no sentido de as políticas funcionarem como retomada dos territórios de domínio das organizações criminosas. Nesse sentido, as UPPs são citadas como o exemplo mais claro deste movimento visto que se afastam de suas concepções originária de aproximação entre polícia e comunidade, utilizando-se mais uma vez da violência como justificativa no combate a própria violência, fazendo com que esta política pública, ao invés de mudar a realidade contribua para a perpetuação dela.

Palavras-Chaves: Violência. Políticas de Segurança Pública. UPPs.

ABSTRACT: Violence in Rio de Janeiro is a phenomenon that has been growing significantly in recent decades, becoming a problem that increasingly generates the need for discussion in the public sphere, as it causes an expressive concern among the entire population regarding the chaos generated by the scenario of constant guerrillas. From there, a concern emerges regarding the need to discuss public policies that work to contain the problems generated by violence in Rio de Janeiro. From this context, reflections on the

\footnotetext{
IPós-Graduado em Inteligência Policial e Penitenciária pela Faculdade Verbo Educacional (2020); PósGraduado em Políticas e Gestão em Segurança Pública pela Universidade Estácio de Sá (2019); PósGraduado em Docência do Ensino Superior pela Faculdade Metropolitana São Carlos (2020); Possuo o Curso Superior em Tecnologia em Segurança Pública pela Universidade Estácio de Sá (2017). Atualmente é Policial Militar na Polícia Militar do Estado do Rio de Janeiro. E Instrutor no Centro de Formação e Aperfeiçoamento de Praças- CFAP/PMERJ. E- mail: antoniojfgomes@ymail.com Lattes: http://lattes.cnpq.br/1598883818728413
} 
assumptions that guide the theme are necessary, seeking to understand how violence in this scenario has been built throughout history based on the relations established between the population and the State, as well as the way in which public policies intervene in this logic built over time. So the main objective of this study is to promote a discussion about the public security policies used to combat violence in Rio de Janeiro. The methodology used is from a bibliographical perspective and a qualitative approach, with a search through physical and digital means in the Scielo and Google Academic databases. In relation to public security, an inversion of values can be observed, in the sense that the policies function as the retaking of territories under the domain of criminal organizations. In this sense, the UPPs are cited as the clearest example of this movement as they move away from their original conceptions of approximation between the police and the community, once again using violence as a justification for combating violence itself, making this policy public, instead of changing reality, contribute to its perpetuation.

Keywords: Violence. Public Security Policies. UPPs.

\section{INTRODUÇÃO}

A violência no Rio de Janeiro é um fenômeno que vem crescendo de uma maneira significativa nas últimas décadas, tornando-se uma problemática que gera cada vez mais a necessidade de discussão no âmbito público, visto que causa uma preocupação expressiva em toda a população frente ao caos gerado pelo cenário de constantes guerrilhas.

Nesse sentido, as favelas configuram-se como principais focos de violência, a qual acontece sob diferentes contextos, principalmente impulsionados pelo tráfico de drogas, o qual é considerado o maior problema em relação os conflitos sociais que assolam estas regiões e as colocam em um estado de alerta contínuo. A partir daí, emerge uma preocupação em relação à necessidade de se implementarem políticas públicas que visem atuar na contenção dos problemas gerados pela violência no Rio de Janeiro.

Em relação a tais políticas de segurança pública, as UPPs (Unidades de Polícia Pacificadoras) têm ganhado um destaque cada vez maior, visto que, em teoria, seriam uma medida de promoção de uma cultura de pacificação em territórios tão conturbados e demarcados pela violência, porém, tem causado problemas expressivos em relação aos confrontos principalmente entre policiais e organizações criminosas, as quais vem afetando de forma extremamente negativa os moradores destas regiões.

A partir deste contexto, fazem-se necessárias reflexões sobre os pressupostos que norteiam a temática buscando a compreensão sobre como a violência neste cenário vem se 
construindo ao longo da história a partir das relações estabelecidas entre a população e o Estado bem como, a forma como as políticas públicas se interpõe nesta lógica construída ao longo do tempo.

Sendo assim, a questão que guia a elucidação do presente estudo é a seguinte? Quais são os paradigmas que norteiam a atual política pública de segurança no Rio de Janeiro e como estes funcionam (ou não) no combate à violência estrutural na cidade?

A hipótese é de que as políticas públicas de segurança são ineficientes visto que, estão fundamentadas em uma lógica de prática policial repreensiva resultante de um longo processo histórico no qual as instituições de poder do Estado funcionam com o objetivo de controle popular, sendo que, neste contexto, as populações que se encontram à margem da sociedade são focos de violência vinda de todas as partes, seja em sua na realidade das relações comunitária quanto por parte da polícia, que utiliza-se das situações de violência para justificar suas próprias ações violentas.

Levando em consideração tais reflexões, os objetivos que nortearam a construção desta pesquisa são:

\section{Objetivo Geral}

- Promover uma discussão sobre as políticas segurança pública empregadas no combate à violência no Rio de Janeiro.

\section{Objetivos Específicos}

- Compreender o processo histórico que fez com que, ao longo dos anos, a violência se tornasse um problema estrutural na cidade do Rio de Janeiro, refletindo sobre como o processo de territorialização contribuiu para que as favelas fossem consideradas o foco dos problemas sociais.

- Discutir sobre a militarização como mecanismo de controle social empregado para a contenção das ações de populações marginalizadas.

- Promover reflexões sobre as UPPs e como esta, que é considerada a principal política de segurança pública do Rio de Janeiro, funciona na prática e na realidade das favelas. 
Como forma alcançar tais objetivos, utilizou-se para a construção do presente estudo a metodologia bibliográfica e de abordagem qualitativa. Para tanto, foram levantadas, publicações dispostas em livros, revistas, periódicos e outros materiais disponíveis em rede física e digital, a partir da busca nas plataformas digitais Google Acadêmico e Scielo, datadas preferencialmente dos últimos io anos.

Sobre a pesquisa bibliográfica, conforme Pizzani et. al. (2012), está centrada em levantar discussões sobre determinada problemática a partir de literaturas já publicadas, promovendo reflexões acerca de teorias e contribuições referidas por diversos autores. Esta metodologia de pesquisa é importante visto que traz conhecimentos empíricos do assunto tratado, promovendo a compreensão da temática bem como discussões de relevância para a sociedade.

Quanto a pesquisa qualitativa, Minayo (2012), afirma que, entendendo o ser humano como um ser histórico, quaisquer ações vindas dos sujeitos dizem respeito à cultura no qual este está inserido bem como os processo históricos que este vivencia, sendo assim, o pesquisador ao debruçar-se sobre uma temática, traz como bagagem os pressupostos construídos ao longo de sua vida, transpondo-os para o conteúdo pelo qual se debruça. Nesse sentido, as compreensões sobre os conteúdos são perpassadas por uma história em movimento, e é nessas relações que se transformam as realidades e os contextos.

Sendo assim, esta pesquisa se justifica frente à necessidade imediata de mudanças em relação à construção de políticas de segurança pública mais humanitárias, as quais venham de encontro com as necessidades de uma população que ao longo da história foi marginalizada e excluída, e nesse sentido, exposta a violência vida de todas as esferas.

Combater a violência demanda um movimento profundo de reflexões sobre os paradigmas que envolvem esta realidade, e neste âmbito, pesquisa que se implicam desta temática são de extrema importância para a construção de uma sociedade menos excludente e na qual a justiça social assuma um caráter de importância para a convivência pacífica entre os sujeitos.

Levando em consideração o exposto, esta pesquisa se divide de forma a elucidar inicialmente considerações sobre a violência e a forma como esta pode ser entendida a 
partir da territorialização do Rio de Janeiro. A segunda sessão diz respeito a discussão sobre a militarização como parte das políticas de segurança pública a qual se continua se configurando como uma forma de controle social, onde a violência é utilizada como via de mão dupla pelos policiais, principalmente das realidades de comunidades marginalizadas.

A terceira sessão discute sobre as UPPs como principal política de segurança pública no Rio de Janeiro, bem como, sua atuação na realidade das favelas e a contradição em relação a utilização da violência como combate a ela própria. Por fim, nas considerações finais são apontadas as principais reflexões construídas ao longo da pesquisa, além de, o aferimento das contribuições e limitações do presente estudo.

\section{VIOLÊNCIA E TERRITÓRIO}

A violência é um problema que vem há tempos preocupando várias cidades brasileiras, configurando-se como uma questão social que mais preocupa a população, além de gerar, diversos debates em relação a forma como atinge endemicamente, em particular, as populações mais vulneráveis (QUINTELA e CARVALHO, 2017). Esse fenômeno cada vez mais recorrente é identificado por diversos autores como "violência urbana".

Segundo Silva (2010, p. 286) a violência urbana não possui uma definição, visto que, diz respeito à um "complexo de práticas que constituem boa parte do conflito social nas cidades brasileiras". Nesse sentido, o autor aponta que é necessário visualizá-la a partir de uma ótica ampla, não podendo ser considerada como "uma paranoia" enaltecida pela mídia, conforme a temática é tratada em diversos estudos.

Assim, Santos (2010) constrói o entendimento de que há uma associação intrínseca entre a violência urbana e uma noção superficial de crime, o qual é reduzido por vezes, à códigos do direito penal, fato que faz com que surjam ameaças reais a integridade da população acometida pelo fenômeno. Então, o como contraponto a este fato o autor enfatiza a necessidade de se compreender a violência urbana a partir do conceito de "sociabilidade violenta".

Nesse sentido, a sociabilidade violenta pode ser entendida como uma forma na qual as relações sociais se constituem, não de forma meramente minimalista, mas sim levando 
em consideração os processos históricos que permeiam as ações cotidianas em nichos comunitários, neste caso, em especificidade no Rio de Janeiro (SANTOS, 2010).

Levando em consideração tais pressupostos, faz se necessário implicar-se na história para permitir a compreensão dos paradigmas que norteiam as relações socias que culminam na sociabilidade violenta no eixo territorial do Rio de Janeiro. Sobre este fato, Marino (2017, p. 2) traz à tona a discussão sobre ordenamento territorial, o qual diz respeito ao "resultado do embate, do enfrentamento entre grupos sociais contrários, do desejo pela imposição de múltiplos interesses socialmente constituídos."

Segundo Marino (2017), o ordenamento territorial refere-se então aos conflitos resultantes de disputas sociais, o qual, demonstra instintivamente a prevalência de grupos sociais que possuíam uma hegemonia dominadora, principalmente em relação à estruturação do Estado. Nesse sentido o autor aponta que a hegemonia de determinada população possui controle sobre ações estatais no sentindo da manutenção de seus interesses.

Sobre este fato, o autor coloca:

Frente ao embate entre hegemônicos e hegemonizados, podemos afirmar que todo ordenamento territorial guarda no seu interior interesses e intenções que buscam subjugar, controlar e dominar os indivíduos que não estejam ligados as diferentes esferas do poder, entre eles o poder do Estado. Mesmo que essas intenções não sejam explícitas, a simples dinâmica de ordenar o espaço leva a uma disciplinarização territorial e, consequentemente, ao controle da população (MARINO, 2017, p.3).

Então, é possível compreender, a partir da representação de ordenamento territorial os primórdios da segregação de grupos específicos na cidade do Rio de Janeiro, visto que, há um longo processo de criminalização de grupos específicos, denotando a repressão sofrida por tais ao longo da história, ocasionando dinâmicas de disputas em relação ao uso da força e do poder de coerção (MARINO, 2017).

Este fato começa a se delinear com a própria forma de colonização brasileira. A cidade do Rio de Janeiro foi palco do início da instituição policial no Brasil, com a chegada da família real portuguesa em I8o8, logo após a abolição da escravidão, e a partir daí, se inicia um movimento no qual a polícia era responsável por garantir “a ordem” na cidade, a qual servia de interesse do Estado e de grupos oligárquicos que ao longo dos anos foi, a partir das práticas policiais, criminalizando toda e qualquer ação não condizente com seus 
interesses, funcionando como uma forma de controle às massas populares (AZEVEDO e NASCIMENTO, 2016).

Nesse sentido, determinados territórios vão sendo demarcados ao longo dos séculos por uma conjuntura que reflete a dominação de grupos que detém os poderes políticos, econômicos, sociais e culturais, empregando suas concepções de mundo como hegemônicas, e nesse movimento, que se produzem funções e significados que fazem prevalecer este domínio ao longo do tempo (BAPTISTA e SANTOS, 202I).

Sobre este fato, Baptista e Santos (2021, p. 379) colocam:

\begin{abstract}
Por isso, o território é o lugar onde o poder é exercido política e juridicamente, que atua sobre um espaço tanto de modo concreto pela dominação (políticoeconômica), portanto, funcional e de troca; quanto de modo subjetivo, pela apropriação (cultural-simbólica), sendo pelo vivido, de uso. É no território que as relações sociais se dão enquanto relações de poder, desde o "anti-poder" da violência até a sutileza do poder simbólico, que compõem o território e a territorialização como "continuum".
\end{abstract}

Nesse sentido, segundo os autores, nesse processo de territorialização, no qual surgem as desigualdades, surgem um sistema de valores que guiam as relações sociais no espaço e no tempo, surgem tensões e conflitos que fazem com que a violência seja uma realidade enraizada, principalmente quando se trata dos espaços ocupados pelas populações vulneráveis, que carregam ao longo de sua história, pressupostos de marginalização e exclusão (MARINO, 2017).

\title{
I. A MILITARIZAÇÃO DAS POLÍTICAS DE SEGURANÇA PÚBLICA
}

Como já sinalizado de antemão, a segurança pública é uma das áreas de maior preocupação do povo brasileiro. As políticas responsáveis por garantir a segurança das cidades, são estruturalmente responsabilidade da União e dos Estados, a qual é realizada fundamentalmente pelos departamentos de polícia civil e militar, de acordo com o que prevê a Constituição Federal de I988 (FERREIRA e MARCIAL, 2015).

O dever do Estado em garantir a "ordem pública" não é um processo recente, porém, tem se intensificado a partir dos anos de 1990 com a criação de instituições como a Secretaria Nacional de Segurança Pública (Senasp) além dá Força Nacional de Segurança Pública e o Sistema Penitenciário Federal. Segundo Ferreira e Marcial (2015), estes órgãos, 
nas últimas décadas vem realizando planejamentos estratégico que visem uma atuação de forma mais efetiva das políticas no âmbito da segurança pública.

Segundo Landim e Siqueira (2013), no contexto dos anos 1990, foram sendo construídas, de maneira gradativa, principalmente em âmbito local, novam modalidades de políticas públicas no campo da segurança e no combate à violência. Segundo as autoras “intervenções passaram a ser formuladas, portanto, também a partir de dispositivos governamentais - incluindo instituições policiais sob seu comando - os quais marcam este cenário de representações e práticas com o forte peso simbólico das instâncias oficiais" (LANDIM e SIQUEIRA, 2013, p. 8).

Sobre este fato, as autoras ainda ressaltam que as ações de combate à violência podem partir de uma gestão na qual haja colaboração entre o poder público e organizações pertencentes à sociedade civil, como uma forma de parceria que atue na base da problemática. Sendo assim, propõe-se uma esfera voltada à a construção de novas relações com as comunidades (LANDIM e SIQUEIRA, 2013, p. 8).

Quanto a criação de tais políticas, Landim e Siqueira ainda apontam:

A segurança pública passa, portanto, cada vez mais, por discursos e tecnologias políticas que implicam construção de novas relações com "comunidades locais" como o Programa Nacional de Segurança com Cidadania (Pronasci), criado em 2008. No Rio de Janeiro, ressaltam-se as novas políticas das Unidades de Polícia Pacificadora (UPPs), acrescidas das UPPs sociais no plano municipal também pautadas por técnicas e discursos de convocação da população à participação (LANDIM e SIQUEIRA, 2013, p.9).

Neste âmbito, para Freire, Murad e Silva (2019), a Constituição de 1988, conhecida como Constituição cidadã, possui um enfoque que trata a Segurança Pública a partir da ótica dos Direitos Humanos, projeto no qual a democracia possui uma retomada representa a retomada dos valores sociais sendo amparada por um aparato jurídico-normativo.

Em contrapartida, os autores apontam que mesmo que a Constituição aponte para a necessidade de políticas humanitária, o que ocorre é que a segurança pública a partir dos anos de 1990, conforme o que foi trazido ao longo da história, tem apresentado tendências de militarização das ações, fato que pode ser observado principalmente nas regiões da periferia do Rio de Janeiro (FREIRE, MURAD e SILVA, 2019). 
Nesse sentido, ainda é afirmado que tais ações, diretas ou indiretas ganham expressividade a partir das “megaoperações” emblemáticas, que são constantemente operacionalizadas pela mídia, as quais são tratadas como um experimento em relação a gestão da segurança pública do Rio de Janeiro e ainda agravadas pela legitimação social (FREIRE, MURAD e SILVA, 2019).

Sobre este fato, Franco (2014) discorre então sobre a militarização da favela no sentido de que a segurança pública, por meio de suas ações policiais (demarcadas por tais operações conforme citadas anteriormente) é modelo predominante nas praticas das instituições policiais. Este fato faz com que haja um problema de via dupla visto que, os grupos que controlam os territórios também se atribuem da militarização para defesa de seus interesses, fazendo com que surjam confrontos que aterrorizam a população local diariamente.

Assim, conforme Baptista e Santos (2021), há a criação de um grande campo de tensões políticas e simbólica, de repercussão estrondosa, no qual as políticas de segurança pública que deveriam, ser a chave para o enfrentamento dos confrontos bélicos entre as organizações criminosas e a polícia, acabam por promover ainda estigmatização dos territórios considerados como marginalizados, como é caso das UPPs, as quais serão discutidas a seguir.

\section{AS UPPS COMO POLÍTICA DE SEGURANÇA PÚBLICA NO RIO DE JANEIRO}

As UPPs fazem parte de uma política de segurança pública implementada no Rio de Janeiro no ano de 2008 (LANDIM e SIQUEIRA, 2013; FRANCO, 2014). A principal inspiração para a criação destas unidades é o modelo de Policiamento Comunitário instaurado na Colômbia, sendo admitidas como o carro chefe das políticas de segurança pública cariocas (FRANCO, 2014).

Segundo Canavês (2012), a primeira UPP do Rio de Janeiro foi inaugurada no final de 2008, tendo nos próximos anos, um aumento expressivo em relação à ocupação de diversas favelas cariocas. Nesse sentido, as contradições já puderam ser observadas nas declarações do próprio Secretário de Segurança Pública do Estado à época, José Mariano Beltrame, o qual afirmo que a ocupação das UPPs seria definitiva nas localidades, 
ocorrendo de forma pacífica ou não (visto que já há uma incitação da utilização da violência como justificável no combate a ela própria).

As UPPs foram então implementadas a partir da égide do discurso de pacificação, no qual, tem-se a denotação da "Polícia da Paz" como o novo modelo de Segurança Pública, no qual o principal objetivo é a aproximação da polícia com a comunidade, no sentido de promover a adesão da sociedade para o combate ao crime no intuito de, segundo Canavês (2012, p. 3)

\footnotetext{
Minimizar dificuldades extremamente corriqueiras na história do policiamento em nosso país, tais como: o uso da força para manter a lei e a ordem, assim como a demanda por parte da sociedade nesse sentido; o corporativismo da classe policial e os conflitos existentes entre as polícias em suas diferentes esferas e demais setores da administração pública.
}

Em contrapartida aos pressupostos que nortearam tal implementação, no qual há um discurso ferrenho em relação a aproximação da polícia com a comunidade, a prática é totalmente oposta. O que ocorreu na realidade é uma atuação que teve como enfoque a delimitação territorial dos locais de ocupação da UPPs, principalmente impulsionados por objetivos políticos de gerar, no cenário internacional, uma confiabilidade em relação aos eventos esportivos de ocorrência nos aos seguintes (BAPTISTA e SANTOS, 2021).

Em relação a este fato, os autores colocam que "apesar da proposta de gerar confiança mútua mesmo a implementação das UPPs não demonstrou qualquer instrumento ou processo que justificasse sua área de abrangência, seu território, com base numa construção dialógica social, entre o poder público, seus agentes a população atendida" (BAPTISTA e SANTOS, 202I, p. 38I).

Nesse sentido, conforme afirma Franco (2014), que as UPPs então se configuram por uma inversão em relação a ocupação dos territórios em que se localizam, os quais antes eram de posse das organizações criminosas, sendo substituídas pela regulação do Estado. Sendo assim, se configuram como uma política pública de segurança fundamentada nas mesmas ideologias construídas ao longo dos séculos, no qual a população marginalizada encontra-se à beira da dominação de grupos detentores do poder hegemônico.

Assim, a polícia acaba-que por conquistar um local estratégico para a manutenção dos objetivos de ordenação e repreensão do Estado. Segundo Franco (2014, p. 123) "o que ocorre é uma propaganda geral pela paz, na qual a polícia, e não a política, ocupa lugar 
central. Esse é mais um dos sintomas do predomínio de uma política de segurança sustentada na militarização".

\section{CONSIDERAÇÕES FINAIS}

Ao longo do estudo foi possível compreender que a violência não é um fenômeno pontual, que possui uma definição específica, mas sim, um processo que vem se construindo ao longo da história pautado nas relações sociais que infundem na sociedade $e$ que representam modelos de perpetuação das desigualdades e marginalização da população que esteve sempre em uma situação de exclusão.

Quando se toma este fato a realidade do Rio de Janeiro, fica clara o quanto tais paradigmas interferem na forma como as configuram os agentes sociais representados pelas instituições policiais, as quais têm como objetivo o estabelecimento da "ordem pública”. o próprio início da polícia no Brasil, e mais especificamente no Rio de Janeiro traz a tona os pressupostos de dominação exercido pelas oligarquias cariocas à época da vinda da família real para o país, no período pós escravidão.

A partir de então, inicia-se um processo de territorialização dos grupos que poderiam oferecer problemas à sociedade dominante da época, fazendo com que houvesse uma criminalização da maioria de suas ações no sentido de repreensão e contenção por parte da polícia para que os conflitos que poderiam prejudicar a classe dominante fossem evitados.

Com a promulgação da Constituição Cidadã em 1988, pregou-se necessidade de criação de políticas públicas fundamentadas nos direitos humanos, as quais estariam em oposição as consecutivas práticas de violência pregadas até então como forma de ordenamento social. Porém, o que pode ser observado, no caso do Rio de Janeiro é somente uma inversão de valores no sentido de as políticas funcionarem como retomada dos territórios de domínio das organizações criminosas.

Nesse sentido, as UPPs são citadas como o exemplo mais claro deste movimento visto que se afastam de suas concepções originária de aproximação entre polícia e comunidade, utilizando-se mais uma vez da violência como justificativa no combate a 
própria violência, fazendo com que esta política pública, ao invés de mudar a realidade contribua para a perpetuação dela.

Sendo assim, pesquisas que levam em consideração a temática são cada vez mais importantes para que possam ser pensadas estratégias e políticas públicas que que invertam a lógica da violência de forma efetiva, visto que esta é uma realidade que além de ter aumentado, tem causado uma preocupação expressiva na população.

Ainda são remotos os estudos que visem estratégias e políticas realmente eficazes no combate a este cenário, fazendo com que haja uma limitação nas discussões. Então, haja vista este fato, sugere-se a realização de estudos que envolvam não só a discussão das políticas públicas de segurança, como também, nova propostas para a problemática da violência nesse âmbito.

\section{REFERÊNCIAS}

AZEVEDO, Rodrigo Ghiringhelli de. NASCIMENTO, Andrea Ana do. Desafios da reforma das polícias no Brasil: Permanência autoritária e perspectivas de mudança Civitas, v. 16, n. 4, p. 653-672, out.-dez, 2016.

BAPTISTA, V. F. SANTOS, W. C. dos. Territórios, políticas e manipulações: a Segurança Pública no olhar da letalidade violenta no Estado do Rio de Janeiro. RPPR, v. 8, n. 3, 377-401, jan/dez. 2021.

CANVÊZZ, F. As UPPs para além do dilema de violência e paz. Revista EPOS, v. 3, n. I, jan/ jun.20I2;

FERREIRA, H. R. S. MARCIAL, E. C. Violência e Segurança Pública em 2023: cenários exploratórios e planejamento prospectivo. Governo Federal, IPEA, 2015.

FRANCO, M. UPP - a redução da favela a três letras: uma análise da política de segurança pública do estado do Rio de Janeiro. Dissertação (Mestrado em Administração), Universidade Federal Fluminense, Niterói, 2014. 
FREIRE, S. M. MURAD, L. C. SILVA, L. T. S. Segurança Pública, mídia e neoconservadorismo: a naturalização da barbarização das relações sociais. Revista de Políticas Públicas, v. 23, n. I, p. 212-231, 2019.

LANDIM, L. SIQUEIRA, R. Trajetos da violência, da segurança pública e da sociedade civil na cidade do Rio de Janeiro. Governo Federal, IPEA, 2013.

MARINO, Leonardo Freire. Geografia e poder: o ordenamento territorial da cidade do Rio de Janeiro e a genealogia da violência policial no Brasil. Biblio 3W, v. 22, n. I.213, 2017.

MINAYO, M. C. Análise qualitativa: teoria, passos e fidedignidade. Ciência \& Saúde Coletiva, I7(3), 621-626. 2012.

PIZZANI, et. al. A arte da pesquisa bibliográfica na busca pelo conhecimento. Revista Digital de Biblioteconomia e Ciência da Informação, v. ı, n. 2, p. 53-66, 2012

QUINTElA, J. P. G. CARVAlHO, J. L. F. Segurança Pública, violência urbana, e expansão do setor de segurança privada no Município do Rio de Janeiro. Revista Produção e Desenvolvimento, v.3, n.2, p.I-20, agosto, 2017.

SILVA, L. A. M. "Violência urbana", segurança pública e favelas - o caso do Rio de Janeiro atual. CADERNO CRH, v. 23, n. 59, p. 283-300, Maio/Ago. 2010. 